\title{
AVALIAĢÃO DO ESTOQUE DE LAGOSTA VERMELHA Panulirus argus NA COSTA BRASILEIRA
}

\section{STOCK ASSESSMENT OF THE RED SPINY LOBSTER Panulirus argus IN THE BRAZILIAN COAST}

\author{
José Augusto Negreiros Aragão1, Israel Hidenburgo Aniceto Cintra² \\ ${ }^{1}$ Instituto Brasileiro do Meio Ambiente e dos Recursos Naturais Renováveis - IBAMA. Av. Visconde Rio Branco, 3900, \\ Fátima, 60.055-172, Fortaleza, CE, Brasil. E-mail: j_aragao@hotmail.com \\ 2 Instituto Socioambiental e dos Recursos Hídricos, Universidade Federal Rural da Amazônia - UFRA. Av. Presidente \\ Tancredo Neves, 2501, Montese, 66.077-530, Belém, PA, Brasil. E-mail: israelcintra@hotmail.com
}

\section{RESUMO}

O estudo trata da avaliação de estoque de lagosta vermelha Panulirus argus, recurso pesqueiro de considerável importância econômica na costa brasileira. As análises foram conduzidas com a utilização da Análise Sequencial de Populações, baseada na composição das capturas por idade, obtida a partir de dados de exportação por tipo comercial, amostras biológicas realizadas em empresas de pesca dos principais estados produtores e captura e esforço de pesca estimado para o período de 2005 a 2015. Os resultados indicam que, apesar das elevadas taxas de mortalidades por pesca e do comprometimento da estrutura por idade/comprimento da população, o estoque apresenta certa estabilidade quanto à sua composição em número e biomassa. A biomassa reprodutiva estimada, no entanto, se encontra bastante reduzida, com uma média $18 \%$ da biomassa sem pesca. Uma redução da mortalidade por pesca, especialmente sobre os indivíduos nas idades 4 e 5 , seria fundamental para recuperar a estrutura da população e poderia resultar em melhores rendimentos da pescaria. Há indícios de resultados positivos neste sentido, a partir das medidas de ordenamento adotadas nos últimos 10 anos, que resultou em considerável diminuição do esforço de pesca.

Palavras-chave: estrutura etária, mortalidade por pesca, biomassa desovante, análise sequencial de população.

Recebido em: 11/12/2017

Aprovado em: 20/08//2018

Publicado online em: 25/03/2019 


\begin{abstract}
The paper deals on the stock assessment of the red spiny lobster Panulirus argus, a fishery resource of considerable economic importance in the Brazilian coast. A Sequential Population Analysis was applied utilizing data on catch composition by age obtained from exports by commercial categories, biological samples carried out in fishing processing plants in the two states of highest landings and estimated catch and effort for the period of 2005 to 2015. Results indicates that, although under high fishing mortalities rates and the compromised age/length structure of the population, the stock presents some stability in terms of composition in numbers and biomass. The estimated spawning biomass, on the other hand, is strongly depleted, with an average of $18 \%$ of the spawning biomass without fishing. A reduction of the fishing mortality, especially on the age 4 and 5 individuals, with the reduction of the fishing effort, would be a fundamental issue aiming the recovery of population structure and the yields of the fisheries. There is some evidence that the management measures adopted in the last 10 years have presented positive results with considerable reduction of the fishing effort.
\end{abstract}

Key words: age-structure, fishing mortality, pawning biomass.

\title{
INTRODUÇÃO
}

No Brasil, as lagostas se constituem num dos mais valiosos produtos da pesca, com suas exportações gerando divisas anuais com valor médio na ordem de 67 milhões de dólares no período de 2010 a 2015 (Mdict-Aliceweb, 2016). Nas pescarias de lagosta na costa brasileira, a lagosta vermelha Panulirus argus (Latreille, 1804) é a principal espécie capturada e exportada totalizando em média 5,3 mil toneladas anuais de peso inteiro nos últimos 10 anos, seguida da lagosta verde com 900 toneladas de peso inteiro, enquanto as contribuições da lagosta pintada e lagosta-sapateira são inexpressivas.

A diminuição da produtividade e rentabilidade das pescarias ao longo dos anos resultou na expansão da área de pesca que, atualmente, compreende o trecho de costa entre os estados do Amapá ao Espírito Santo. Em paralelo, o número de embarcações industriais diminuiu gradativamente e, a frota é composta integralmente por barcos de madeira motorizados, geralmente com comprimento variando entre 12 e 16 m, por embarcações motorizadas de pequeno porte, e por grande número de embarcações a vela (Castro-Silva \& Rocha, 1999). Vários trabalhos de avaliação de estoque de lagostas foram realizados no Brasil até a década de 1990, com dados de captura e esforço de pesca, utilizando modelos gerais de produção baseados no pressuposto de equilíbrio da população. Erhardt \& Aragão (2007) utilizaram programa ADAPT, com dados de composição das capturas por comprimento e idade, e realizaram nova avaliação de estoque do recurso.

Mais recentemente, foi realizado um estudo baseado em análise de coortes para avaliar a efetividade dos defesos como medida de manejo (Silva \& Fonteles-Filho, 2011). Cruz et al. (2013) também apresentaram estimativas de rendimento máximo sustentável, baseadas em dados de captura e esforço e métodos de "área varrida". Em 2015, foi realizada outra análise baseada em modelos de produção com abordagem bayesiana (Andrade, 2015). Nos estudos mencionados acima se assume um estoque único, e, de maneira geral, 
que vem sendo sobrepescado. Apesar disso, a aparente estabilidade das quantidades exportadas (Mdict/Aliceweb, 2015) sugeria indícios que a atividade vinha sendo exercida de forma sustentável.

Desde a década passada, no entanto, a crescente insuficiência de dados biológicos e de monitoramento estatísticos dos desembarques e da composição das capturas de lagosta vem dificultando a realização de análises mais consistentes, especialmente com modelos mais detalhados, estruturados por idade (ou comprimento). Porém, estão disponíveis no Instituto Brasileiro do Meio Ambiente e dos Recursos Naturais Renováveis - IBAMA, e nas próprias empresas de pesca, informações sobre exportações em peso por tipo comercial e os totais exportados pelo país são informados no site do Mistério da Indústria, Desenvolvimento e Comércio (MDICT). Em conjunto com outros dados e amostras também disponíveis no IBAMA, estes dados permitiram a realização deste trabalho, onde se estima a estrutura de comprimentos/idade das capturas e se faz uma avaliação do estoque da lagosta vermelha, utilizando a Análise Sequencial de Populações (Megrey, 1989).

Incertezas, geralmente não levadas em conta em outras abordagens, foram incorporadas na análise, com o cálculo de intervalos de confiança para as quantidades de interesse, como biomassa do estoque. As estimativas obtidas para o cenário atual serão úteis nos processos de tomada de decisão visando ao adequado manejo deste importante recurso pesqueiro.

\section{MATERIAL E MÉTODOS}

Os dados utilizados no presente trabalho apresentam características diversificadas e provém de diferentes fontes. Ao final do trabalho de resgate e organização das informações se obteve uma série temporal para o período de 1989 a 2015, cujos componentes são descritos a seguir:

a) Exportações por categoria comercial: quantidades $(\mathrm{kg})$ de lagosta exportadas por categoria ou tipo comercial pelas empresas de pesca do Ceará, no período de 2005 a 2015, obtidas nos certificados de exportação arquivados no IBAMA, bem como aquelas divulgadas pelo Sindicato das Empresas de Frio e Pesca (SINDPESCA), e dados semelhantes obtidos pelo IBAMA junto às empresas processadoras do Rio Grande do Norte. Os tipos comerciais de lagosta são estabelecidos com base no peso médio dos indivíduos (caudas) no padrão americano de medidas. O tipo 2 corresponde a caudas com peso médio de duas onças (56,7 g), o tipo 3 a três onças (85,0 g) e assim sucessivamente, até o tipo “20+" (> 567,0 g).

b) Total anual de lagosta exportada: quantidade total de lagostas exportadas por empresas brasileiras, no período de 2005 a 2015, obtido no site do sistema Aliceweb, mantido pelo Mdict. As quantidades são discriminadas por estado, mas não por tipo comercial.

c) Amostras por comprimento dos tipos comerciais: amostras de composição por comprimentos e da proporção por espécie, para cada tipo, no período de 1999 a 2006, para o Ceará, e no período de 1989 a 1994, para o Rio Grande do Norte, obtidas junto às Superintendências do IBAMA nos dois estados. Embora se reconheça que a proporção de espécies dentro de cada tipo possa variar anualmente, considerou-se que estas alterações não teriam sido expressivas nos últimos anos, assumindo-se como representativa para o período do estudo a proporção encontrada nestas amostras.

d) Esforço de pesca e captura controlada: esforço de pesca controlado em número de dias de mar, e capturas controladas, de expressivo número de viagens de pesca, nos principais 
estados produtores, Ceará e Rio Grande do Norte, no período de 2005 a 2014, obtidos para as diversas pescarias (um tipo de barco operando com certa arte de pesca), junto ao programa de levantamento estatístico da pesca denominado "Estatpesca", conduzido pelo IBAMA nos dois estados.

A sistematização dos dados foi feita considerando as pescarias do Ceará representativas da maior parte das pescarias do país, uma vez que o estado se posiciona como principal produtor e, segundo Castro-Silva \& Rocha (1999), sua frota é a mais tradicional em operação, atuando em praticamente toda a área de pesca da lagosta. Assim, se passará a chamar de "Ceará+" o grupo de estados que incluí também Pará, Piauí, Pernambuco, Bahia e Espírito Santo. Ressalte-se que a produção de lagostas atribuída ao estado de Pernambuco tem origem predominantemente em outros estados, principalmente na Bahia. As pescarias do Rio Grande do Norte, segundo maior produtor, foram consideradas representativas também daquelas realizadas no estado da Paraíba. Nestes dois estados operam frotas de menor raio de ação, com capacidade de deslocamentos limitados para áreas mais distantes (Ivo et al., 2013) e o grupo composto por estes dois estados passará a ser chamado "RNorte+". A captura total em peso, para o país como um todo, foi estimada com base nas quantidades exportadas. Praticamente toda a produção de lagostas, especialmente da lagosta vermelha, é processada industrialmente para exportação.

Embora não existam estudos mais aprofundados, tem sido assumido, historicamente, que as exportações correspondem a 95\% da captura total. Neste trabalho as estimativas de captura total em peso para o país como um todo também se baseiam nessa proporção. Mesmo a partir de 2008, quando os Estados Unidos da América (EUA) proibiu importação de lagostas abaixo do "tipo 5" (aproximadamente 15,5 cm de cauda), considera-se o percentual de 95\% válido, pois, de acordo com os dados extraídos do sistema ALICEWEB, aumentaram as exportações para outros países, o que compensaria a redução da exportação para os EUA.

A partir da participação relativa em peso de cada tipo na parcela das exportações anuais controladas no Ceará e Rio Grande do Norte, foi feita a expansão para o total geral exportado por tipo, para cada um dos dois grupos de estados (Ceará+ e RNorte+), obtendo-se, assim, uma estimativa do total exportado em peso por tipo para todo o país. As quantidades totais em peso exportadas por tipo, para cada grupo de estados, foram convertidas para números totais de indivíduos com base na estimativa de peso médio de cauda em cada tipo. Deve-se ressaltar aqui que não estão sendo consideradas as capturas de lagostas abaixo do tamanho mínimo permitido de captura, uma vez que não existem fontes consistentes de informações sobre estas quantidades ou sobre sua composição por tamanhos. No entanto, durante as análises, este aspecto foi considerado para efeito de estimação composição da estrutura etária da população em números.

As quantidades totais em números por tipo comercial, exportadas pelos grupos de estados "Ceará+" e "RNorte+", foram convertidas para números por classes de comprimento de $10 \mathrm{~mm}$ de amplitude, com auxílio das distribuições de frequência de comprimento amostrais, e também da proporção de lagosta vermelha ( $P$. argus), associada a cada tipo. Obtiveram-se, assim, distribuições de frequência anuais por classe de comprimento, para as capturas totais estimadas de lagosta vermelha em cada ano, para cada um dos dois grupos de estados. A soma dos números totais de indivíduos por classe de comprimento para os dois grupos resulta na estimativa da distribuição de frequência total para o país. Este procedimento não levou em conta a separação dos indivíduos por sexo uma vez que, segundo Ivo \& Pereira (1996), não existem diferenças significativas nos parâmetros de cres- 
cimento entre machos e fêmeas e, como demonstrado a seguir, a proporção entre sexos também não apresenta diferenças significativas.

A conversão das distribuições de frequência por comprimento total para distribuição de frequência por idade em anos, foi feita com a utilização inversa da equação de von Bertalanffy e os parâmetros de crescimento apresentados por Ivo \& Pereira (1996): $t=-\left(10,232 /\right.$ ano $\left.^{-1}\right) \ln (1-$ Lt $430 \mathrm{~cm})$.

Inicialmente, o ponto médio de cada classe de comprimento foi convertido diretamente para a idade correspondente e depois os números estimados para cada idade foram agrupados considerando intervalos de um ano da seguinte forma: os números correspondentes à idade de 0,6 até 1,5 foram agrupados na idade 1.0; de 1,6 até 2,5 na idade 2.0; e assim por diante. Este processo, conhecido como "slicing" (Sparre \& Venema, 1997), resultou em nove grupos de idades relativas (idade 2 até idade 10).

O esforço de pesca nominal, em termos de dias de mar, para o período de 2005 a 2014, foi estimado pela divisão da estimativa da captura anual total do país, pela captura por unidade de esforço de pesca (CPUE), em quilogramas por dias de mar, da frota motorizada que opera com caçoeira no Ceará, que seria a principal frota atuante no referido período.

Uma vez obtida uma estimativa dos números totais capturados por idade e considerando-se a estimativa de mortalidade natural $M=0,313 a n o^{-1}$ (Ivo \& Pereira, 1996), a avaliação do estoque foi feita utilizando-se um modelo de análise sequencial de populações estruturado por idades (Statistical Catch at Age) (Megrey, 1989), detalhadamente descrito por Haddon (2011). O modelo combina capturas por idade, mortalidade natural e um índice de abundância, podendo incluir outras informações auxiliares, para estimar taxas de mortalidade por pesca, seletividade por idade e composição da população em números por idade. Para estimativa dos parâmetros, procura-se minimizar as diferenças entre as capturas observadas e as capturas estimadas, e entre as CPUE observadas e estimadas.

O ajuste começa com a estimação preliminar do número aproximado de indivíduos em cada coorte, feita inicialmente através da "Análise de Coorte de Pope" (Pope, 1972), utilizando-se a expressão modificada por MacCall:

$$
N_{a, y}=N_{a+1, y+1} e^{M}+C_{a, y}\left(\frac{M}{1-e^{-M}}\right)
$$

Onde " $N$ " corresponde ao número de indivíduos na população, " $C$ " ao número de indivíduos capturados, " $a$ " faz referência à idade, " $y$ " ao ano e " $M$ " a mortalidade natural, considerada constante ao longo de toda a existência da coorte.

Para o último ano e idades mais velhas, o número aproximado de indivíduos pode ser obtido pela expressão:

$$
N_{a, y}=\left[\frac{C_{a, y}}{\left(1-e^{\left.-Z_{a, y}\right)}\right.}\right]\left(\frac{Z_{a, y}}{F_{a, y}}\right)
$$

Uma vez estimada a matriz de número aproximado de indivíduos por idade por ano, uma estimação aproximada das mortalidades por pesca $(F)$, para cada idade, é também obtida com a aplicação da expressão:

$$
F_{a, y}=\operatorname{In}\left(\frac{N_{a, y}}{N_{a+1, y+1}}\right)-M
$$

No processo de aproximação, os números gerados pela análise de coorte para a última idade são estimados considerando-se simplesmente que na idade seguinte o número 
de indivíduos é zero. As estimativas de números por idade dos anos mais recentes, que correspondem às coortes incompletas, exatamente aquelas de maior interesse para a análise, são bastante irreais. Assim, partindo dos números iniciais, estimativas mais razoáveis são obtidas por iteração partindo da equação fundamental da análise de coorte:

$$
0=\left[1-\frac{M}{\operatorname{In}\left(\frac{N_{a, y}}{N_{a+1, y+1}}\right)}\right]\left(N_{a, y}-N_{a+1, y+1}\right)-C_{a, y}
$$

Como no último ano de dados somente a última idade representa uma coorte completa, sendo as idades anteriores cada vez mais incompletas, para se obter números mais aproximados nestas coortes se utiliza novamente a expressão:

$$
N_{y}=\frac{C_{y}}{\left(1-e^{-z}\right)} * \frac{F_{y}+M}{F_{y}}
$$

Sendo as estimativas de mortalidade por pesca determinadas para as coortes completas pela equação a seguir:

$$
F_{y}=\operatorname{In}\left(\frac{N_{y}}{N_{y+1}}\right)-M
$$

Uma vez estimadas as mortalidades por pesca para as coortes completas, o coeficiente de capturabilidade para cada classe de idade pode ser obtido com a expressão $F y=$ $q_{a} E_{y^{\prime}}$ utilizando-se o esforço de pesca nos anos em que as coortes completas foram capturadas. O coeficiente de capturabilidade por idade é, então, estimado por $q_{a}=F_{y} / E_{y}$. Dadas as estimativas de $q_{a}$ e o esforço no último ano de dados, estimativas das mortalidades por pesca terminais ( $F_{y}$ terminais) são obtidas e, a cada iteração, números mais aproximados por idade para as coortes incompletas no último ano podem ser obtidos. Com este procedimento se obtém estimativas de números iniciais, da mortalidade por pesca por idade para as coortes completas, e das mortalidades terminais (último ano).

Na etapa de ajuste da Análise Sequencial de População, descrita a seguir, se utiliza a seguinte notação: $F_{y}$ é a taxa de mortalidade por pesca no ano $y$, para os comprimentos/ idades expostos à seletividade total; $F_{a, y}$ é a taxa de mortalidade por pesca para cada idade $a$ e ano $y$, onde $F_{a, y}=S_{a} \hat{F}_{y} ; \hat{F}_{y}$ é a taxa de mortalidade por pesca ajustada para o ano $y$; e $s_{a}$ seletividade na idade $a$.

Assume-se que a seletividade (proporção retida) por idade pode ser descrita por uma curva logística:

$$
S_{a}=\frac{1}{1+e^{\left[-\operatorname{In}(19) \frac{\left(a-a_{50 \%}\right)}{\left(a_{95 \%}-a_{50 \%}\right)}\right]}}
$$

Onde $a_{50 \%}$ é o parâmetro que representa a idade correspondente à seletividade de $50 \%, a_{95 \%}$ é o parâmetro que representa a idade correspondente a $95 \%$ da seletividade. Os parâmetros da curva são estimados no processo de iteração.

Os valores das taxas de mortalidade por pesca correspondente à seletividade total (100\% de retenção) para cada ano $\left(F_{y}\right)$ são tratados como parâmetros e estimados por iteração. As mortalidades por pesca estimadas para cada idade e ano $\left(F_{a, y}\right)$, por sua vez, são combinadas com a mortalidade natural $(M)$ para cálculo de taxas de sobrevivência para 
cada idade e cada ano, $\left[S_{a, y}=\mathrm{e}^{-\left(M+s_{a} \hat{F} y\right)}\right]$ que são utilizadas para estimar toda a matriz de números por idade, partindo-se dos números preliminares obtidos na etapa anterior:

$$
N_{a+1, y+1}=N_{a, y} e^{-M} e^{-s_{a} F y}
$$

Onde $N_{a, y}$ é o número de indivíduos na idade $a$ no ano y e $N_{a+1, y+1}$ é o número de indivíduos na idade $a+1$ nos ano $y+1$.

Finalmente, o ajuste do modelo é obtido estimando-se os valores $N_{a, 1}$ 's para todas as idades no ano 1 [Nest ${ }_{y, a}=\exp ^{\operatorname{Ln}\left(\mathrm{Nini}_{\mathrm{y}, a}\right)}$ onde "ini" se refere a inicial] e todos $N_{a, y}$ correspondentes à primeira classe de idade $\left[\right.$ Nest $\left._{y, a}=\exp ^{\operatorname{Ln}\left(\operatorname{Rini}_{y, a}\right)}\right]$ (neste caso $a=2, N_{2, y}=R$ ), a partir dos quais são estimados os números nas idades e anos seguintes $\left[N_{a+1, y+1}=N_{a, y} e^{-M e-s a F^{\wedge} y}\right]$, os números explotáveis por idade $\left(N E x p_{a, y}=S_{a} N_{y, a}\right)$ e as capturas estimadas para cada idade e ano:

$$
\hat{C}_{a, y}=\frac{F_{a, y}}{M+F_{a, y}} N_{a, y}\left[1-e^{-\left(M+F_{a, y}\right)}\right] \text { ou } \hat{C}_{a, y}=\frac{F_{a, y}}{M+F_{a, y}} N_{a, y}\left[1-S_{a, y}\right]
$$

O processo de interação tem como função objetiva principal:

$$
S S R_{C}=\Sigma_{a} \Sigma_{y}\left(\operatorname{In} C_{a, y}-\operatorname{In} \hat{C}_{a, y}\right)^{2}
$$

No entanto, se há informações auxiliares de sobre o esforço de pesca nominal anual (E), as mesmas podem ser utilizadas na iteração. Combina-se o esforço com o coeficiente de capturabilidade $(q)$ de forma a se obter um cálculo da mortalidade por pesca (F_y=q^E_y), que é comparado com a mortalidade por pesca estimada para as idades que estariam exposta à seletividade total (100\% de retenção no caso da curva logística):

$$
S S R_{E}=\Sigma_{y}\left[\operatorname{Ln}\left(\hat{F}_{y}\right)-\left(\operatorname{Ln}(\hat{q})+\operatorname{Ln}\left(E_{y}\right)\right)\right]^{2}
$$

As duas funções objetivas acima correspondem a somas de quadrados de resíduos a serem minimizadas. Em ambos os casos se assume uma estrutura exponencial multiplicativa para o erro, o que resulta nos logarítimos que aparecem nas funções objetivas.

Tendo em vista que o esforço de pesca (informação auxiliar) foi obtido simplesmente pela divisão da captura total anual estimada, pela estimativa da CPUE da arte de pesca "caçoeria", optou-se por se atribuir menor peso para a função objetiva que considera o esforço. Peso 1 foi atribuído à função referente à captura em número, enquanto que foi atribuído peso relativo de 0.5 para a função que trata do esforço.

Há ainda a possibilidade de se considerar uma estrutura para a relação estoque-recruta que resultaria em uma terceira função objetiva. Neste trabalho assumiu-se a relação estoque-recrutamento de Beverton-Holt, pois, de acordo com Cobb \& Caddy (1989), seria mais adequada para a lagosta vermelha. Os valores obtidos são então comparados com os resultados do modelo: $S S R_{R}=\left(\operatorname{LnN}_{r, y+r}-\operatorname{Ln} \widehat{N}_{r, y+r}\right)^{2}$.

Uma vez que se dispõe do esforço de pesca, as taxas de captura estimadas podem ser obtidas pela expressão: $\hat{I}_{y}=q B_{y}^{E}=q \sum_{a} w_{a} s_{a} N_{a, y} I$.

Onde: $I^{\wedge}{ }_{y}$ taxa de captura estimada; $q$ coeficiente de capturabilidade; $B_{y}^{E}$ biomassa explotável no ano $y ; w_{a}$ peso médio do indivíduo na idade $a$; sa seletividade específica da idade; $N_{a, y}$ números na idade $a$ no ano $y$. As diferenças entre as taxas de captura assim obtidas e as taxas de captura observadas podem ser usadas para a construção de mais uma função objetiva: $S S R_{I}=\sum_{y}\left[\operatorname{In}\left(I_{y}\right)-\operatorname{In}\left(\hat{I}_{y}\right)\right]^{2}$.

Ou seja, o ajuste do modelo é feito procurando-se minimizar o somatório dos quatro valores, embora com pesos diferentes: $S S R_{T}=S S R_{C}+S S R_{E}+S S R_{R}+S S R_{I}$. 
Uma vez concluído o ajuste, a composição da estrutura etária da população, caso estivesse submetida apenas à mortalidade natural, sem o impacto da pesca, é estimada partindo-se de um recrutamento médio estimado para os anos em análise. Este procedimento permite comparar a "estrutura pristina teórica" com a estrutura observada (estimada) atualmente.

Por fim, a utilização de um procedimento de "bootstrap", baseado na reamostragem dos resíduos das capturas estimadas e observadas, permite que se faça uma avaliação de incertezas associadas ao processo de estimação. No presente trabalho, foram obtidas estimativas de biomassa do estoque em 1000 simulações e a distribuição de frequência relativa dos valores permitiu que se tivesse uma ideia da amplitude da incerteza das estimativas.

\section{RESULTADOS}

A produção total de lagostas no país, no período de 2005 a 2015, estimada a partir dos dados de exportação (MDICT-ALICEWEB), influenciada principalmente pelo volume expressivamente maior corresponde ao grupo "Cearát", apresenta tendência geral decrescente, com um pico de 2.557,6 t em 2010 e uma queda acentuada em 2012 (Tabela 1). Nota-se certa recuperação em 2013, atingindo 2.027,8 t, se mantendo praticamente no mesmo nível em 2014, com 1.926,8 t, e no ano de 2015, estimada em 1.944,2 t. A produção somente do grupo "R.G. Norte+", mostra picos de produção em torno de 370 t em 2007/2008 e, desde então, tem tendência geral decrescente, totalizando apenas 146,1 t em 2014. Um pico de 192,9 é observado em 2013 e estima-se uma forte recuperação para 2015, atingindo 265,5 t. O esforço de pesca total das pescarias, estimado a partir da produção total dividida pela CPUE nominal, em quilogramas por dia de mar, das lanchas operando com caçoeira no Ceará, apresentou tendência de forte redução a partir de 2005, passando de 416,1 mil dias de mar, para apenas 260,6 mil dias de mar, em 2008. Esta queda se acentuou em 2009, conforme a Tabela 1, totalizando apenas 129,9 mil dias de mar. A partir daí, o esforço de pesca mostrou lenta recuperação, atingindo 177,0 mil dias de mar em 2014. Deve-se ressaltar, novamente, que se trata de valores nominais obtidos por um processo de certa forma empírico.

Tabela 1 - Exportações e produção estimada de caudas de lagosta $(\mathrm{kg})$ no Brasil, por grupo de estados, e esforço de pesca (milhares de dias de mar) estimado, no período de 2005 a 2015.

\begin{tabular}{cccccccc}
\hline & \multicolumn{3}{c}{ Exportação } & \multicolumn{3}{c}{ Produção Estimada } & \multicolumn{2}{c}{ Esforço (x1000) } \\
Ano & Ceará+ & R.G.Norte+ & Total & Ceará+ & R.G.Norte+ & Total & Dias Mar \\
\hline 2005 & 2.027 .379 & 256.419 & 2.283 .798 & 2.134 .084 & 269.915 & 2.403 .998 & 416,1 \\
2006 & 1.926 .399 & 180.987 & 2.107 .386 & 2.027 .788 & 190.513 & 2.218 .301 & 371,0 \\
2007 & 1.842 .303 & 347.606 & 2.189 .909 & 1.939 .266 & 365.901 & 2.305 .167 & 309,3 \\
2008 & 1.870 .058 & 356.458 & 2.226 .517 & 1.968 .482 & 375.219 & 2.343 .702 & 260,6 \\
2009 & 1.826 .042 & 152.956 & 1.978 .998 & 1.922 .149 & 161.006 & 2.083 .155 & 129,9 \\
2010 & 2.282 .450 & 147.280 & 2.429 .730 & 2.402 .579 & 155.031 & $2.557,611$ & 148,9 \\
2011 & 2.078 .172 & 166.832 & 2.245 .004 & 2.187 .549 & 175.613 & 2.363 .162 & 131,5 \\
2012 & 1.365 .858 & 136.205 & 1.502 .063 & 1.437 .745 & 143.374 & 1.581 .119 & 132,3 \\
2013 & 1.743 .123 & 183.260 & 1.926 .383 & 1.834 .867 & 192.905 & 2.027 .772 & 168,5 \\
2014 & 1.691 .675 & 138.748 & 1.830 .423 & 1.780 .711 & 146.051 & 1.926 .761 & 177,0 \\
2015 & 1.594 .757 & 252.268 & 1.847 .025 & 1.678 .691 & 265.545 & 1.944 .236 & Não disponível \\
\hline
\end{tabular}

Os números de lagostas amostradas nos diversos tipos comerciais, com a estimativa da participação relativa das diferentes espécies no conjunto das exportações, indicam evidente predominância da lagosta vermelha (P.argus) nas pescarias. No Ceará isso fica mais evidente, com a P. argus contribuindo com 91,1\% em peso e 80,7\% em número. No Rio 
Grande no Norte, a participação da P. argus cai para 68,1\% em peso e 52,5\% em número, ficando a P. laevicauda com 31,9\% das exportações em peso e 47,5\% em número (Tabela 2). No total das exportações/produção do Ceará e Rio Grande do Norte, a participação relativa da $P$. argus no período considerado, quando ponderada pela produção total, gira em torno de $72,4 \%$ em peso e $68,5 \%$ em número, influenciada pelo volume bem superior do Ceará.

Tabela 2 - Quantidade $(\mathrm{kg})$, número e proporção de caudas de lagostas por espécie nas exportações controladas do Ceará (1999/2006), e Rio Grande do Norte (2009/2012).

\begin{tabular}{lcccccccc}
\hline \multirow{2}{*}{ Espécie } & \multicolumn{3}{c}{ Ceará } & \multicolumn{4}{c}{ Rio Grande do Norte } \\
& $\mathrm{kg}$ & $\%$ & Número & $\%$ & $\mathrm{Kg}$ & $\%$ & Número & $\%$ \\
\hline Vermelha & 6.165 & 91,1 & 24.376 & 80,7 & 374.515 & 68,1 & 1.566 .601 & 52,5 \\
Verde & 586 & 8,7 & 5.700 & 18,9 & 175.142 & 31,9 & 1.728 .069 & 47,5 \\
Outras & 15 & 0,2 & 137 & 0,5 & & & & \\
\hline Total & 6.766 & 100,0 & 30.213 & 100,0 & 549.657 & 100,0 & 3.294 .670 & 100,0 \\
\hline
\end{tabular}

Fonte: IBAMA Ceará e Rio Grande do Norte.

Em relação à composição das amostras por sexo, verificou-se que não existem diferenças significativas na proporção entre macho e fêmeas (Tabela 3). Tendo em vista que também não foram encontradas diferenças significativas nos parâmetros de crescimento, o processo de avaliação foi conduzido, sem considerar a separação por sexo.

Tabela 3 - Proporção em número por sexo de P. argus nas amostras biológicas de realizadas nas indústrias nos principais estados produtores no Brasil.

\begin{tabular}{lccccccccc}
\hline \multirow{2}{*}{ Sexo } & \multicolumn{3}{c}{ Ceará } & \multicolumn{4}{c}{ Rio Grande do Norte } & \multicolumn{3}{c}{ Total } \\
& Número & $\%$ & $X^{2}(1 d f)$ & Número & $\%$ & $X^{2}(1 d f)$ & Número & $\%$ & $X^{2}(1 d f)$ \\
\hline Fêmea & 12.870 & 52,8 & 0,000 & 16.785 & 52,4 & 0,000 & 29.655 & 52,6 & 0,000 \\
Macho & 11.506 & 47,2 & & 15.264 & 47,6 & & 26.770 & 47,4 & \\
\hline Total & 24.376 & 100,0 & & 32.049 & 100,0 & & 56.425 & 100,0 & \\
\hline
\end{tabular}

Fonte: IBAMA Ceará e Rio Grande do Norte

As quantidades controladas de caudas de lagostas exportadas, em quilogramas por tipo comercial (Tabelas 4), para o período de 2005 a 2015, foram obtidas nas declarações de exportação, apresentadas pelas empresas de pesca ao IBAMA, no Ceará, e por levantamentos sistemáticos, realizados pela equipe do IBAMA, junto às empresas de processamento no estado do Rio Grande do Norte. No caso do Ceará os dados para o ano de 2014 e 2015, no entanto, foram aqueles divulgados pelo Sindfrio (Cedepesca, 2015). Nos dois estados, os dados controlados representam, em geral, parte expressiva do total exportado.

A produção estimada de lagosta para os dois grupos de estados (Ceará+e R.G.Norte+), por tipo comercial, obtidas a partir das quantidades controladas em número por tipo comercial, no Ceará e Rio Grande do Norte, foram somadas resultando na quantidade total de lagostas produzidas por tipo comercial no Brasil, no período de 2005 a 2015 (Tabela 5).

Os números estimados de indivíduos de $P$. argus capturados por classe de comprimento são apresentados na Tabela 6 . Na linha mais abaixo na tabela se encontram também os pesos médios de cauda em cada ano que, embora não apresentem comportamento bem definido, mostram ligeira tendência de queda até 2009. Nos anos seguintes há certa tendência de recuperação, embora o menor peso médio do período seja observado em 2013. 
Tabela 4 - Exportações anuais controladas $(\mathrm{kg})$ de caudas de lagostas, por tipo comercial, pelo estado do Ceará e Rio Grande do Norte, no período de 2005 a 2015.

\begin{tabular}{|c|c|c|c|c|c|c|c|c|c|c|c|c|c|c|}
\hline \multirow{2}{*}{ Ano } & \multicolumn{13}{|c|}{ Categoria Comercial } & \multirow{2}{*}{$\begin{array}{l}\text { Total } \\
\text { Geral }\end{array}$} \\
\hline & 2 & 3 & 4 & 5 & 6 & 7 & 8 & 9 & $10 / 12$ & $14 / 12$ & $14 / 16$ & $16 / 20$ & 20/UP & \\
\hline \multicolumn{15}{|c|}{ Ceará } \\
\hline 2005 & 36 & 3.592 & 13.771 & 11.176 & 16.112 & 16.402 & 13.499 & 17.944 & 42.783 & 22.988 & 12.955 & 9.144 & 4.554 & 184.956 \\
\hline 2006 & 0 & 5.787 & 21.188 & 17.813 & 15.691 & 14.857 & 10.918 & 13.238 & 28.396 & 13.659 & 9.487 & 5.533 & 1.324 & 157.891 \\
\hline 2007 & 0 & 9.904 & 33.831 & 41.668 & 34.629 & 31.128 & 15.049 & 23.686 & 54.777 & 13.895 & 5.025 & 4.662 & 617 & 268.871 \\
\hline 2008 & 0 & 22.348 & 156.947 & 227.426 & 172.495 & 145.526 & 108.437 & 101.419 & 190.169 & 105.882 & 55.109 & 27.295 & 1.324 & 1.314 .378 \\
\hline 2009 & 54 & 30.058 & 231.902 & 226.659 & 263.955 & 170.951 & 153.348 & 130.202 & 196.834 & 82.954 & 42.593 & 25.033 & 853 & 1.555 .396 \\
\hline 2010 & 0 & 40.525 & 99.661 & 141.510 & 139.079 & 172.384 & 247.895 & 193.422 & 335.394 & 155.646 & 86.328 & 65.917 & 5.115 & 1.682 .878 \\
\hline 2011 & 3.628 & 41.272 & 108.650 & 118.518 & 100.121 & 99.286 & 98.883 & 106.422 & 176.525 & 88.439 & 52.209 & 25.725 & 3.266 & 1.022 .944 \\
\hline 2012 & 0 & 17.781 & 45.770 & 57.331 & 49.256 & 44.140 & 71.065 & 52.203 & 53.087 & 30.780 & 9.773 & 6.609 & 707 & 438.504 \\
\hline 2013 & 0 & 50.794 & 179.864 & 165.624 & 394.177 & 101.659 & 110.225 & 76.085 & 105.811 & 67.011 & 16.381 & 13.115 & 91 & 1.280 .836 \\
\hline $2014\left(^{*}\right)$ & 127 & 1.633 & 131.142 & 185.282 & 217.197 & 189.982 & 224.944 & 197.910 & 345.436 & 107.011 & 108.281 & 64.809 & 218 & 1.773 .972 \\
\hline 2015 & 0 & 82.424 & 119.763 & 107.978 & 102.315 & 97.810 & 84.598 & 72.087 & 183.010 & 67.136 & 50.967 & 51.989 & 24 & 1.020 .101 \\
\hline \multicolumn{15}{|c|}{ Rio Grande do Norte } \\
\hline 2005 & 118 & 18.734 & 37.867 & 32.982 & 24.871 & 24.068 & 25.098 & 20.952 & 31.753 & 22.776 & 11.798 & 11.041 & 708 & 262.766 \\
\hline 2006 & 3.737 & 26.416 & 48.949 & 40.078 & 26.851 & 22.551 & 18.415 & 15.258 & 17.471 & 11.556 & 4.064 & 4.771 & 9.362 & 249.481 \\
\hline 2007 & 3.429 & 21.991 & 45.505 & 61.744 & 43.654 & 35.762 & 29.411 & 21.029 & 36.088 & 17.092 & 7.366 & 7.820 & 163 & 331.055 \\
\hline 2008 & 1.379 & 18.108 & 69.836 & 67.622 & 46.775 & 42.692 & 37.993 & 28.414 & 53.053 & 32.332 & 17.164 & 16.257 & 381 & 432.006 \\
\hline 2009 & 200 & 15.041 & 14.352 & 30.373 & 28.159 & 22.807 & 14.025 & 8.455 & 10.415 & 5.988 & 2.395 & 1.978 & 0 & 154.188 \\
\hline 2010 & 36 & 11.803 & 16.502 & 15.859 & 10.769 & 8.473 & 7.258 & 6.432 & 13.019 & 11.476 & 6.015 & 6.269 & 91 & 114.002 \\
\hline 2011 & 236 & 20.448 & 22.517 & 26.615 & 17.545 & 15.368 & 12.719 & 9.507 & 14.629 & 10.723 & 6.006 & 6.418 & 73 & 162.804 \\
\hline 2012 & 0 & 12.623 & 12.935 & 21.130 & 13.640 & 11.553 & 9.952 & 7.965 & 13.986 & 8.918 & 7.249 & 7.729 & 36 & 127.717 \\
\hline 2013 & 109 & 15.831 & 18.992 & 22.775 & 15.590 & 12.837 & 9.507 & 6.242 & 11.140 & 7.575 & 5.067 & 5.262 & 0 & 130.927 \\
\hline 2014 & 18 & 17.559 & 18.394 & 21.855 & 15.513 & 10.924 & 7.480 & 3.760 & 6.545 & 3.715 & 2.873 & 3.234 & 0 & 111.870 \\
\hline 2015 & 0 & 18.874 & 28.949 & 31.407 & 27.257 & 17.005 & 14.304 & 9.126 & 13.381 & 7.738 & 4.745 & 6.963 & 1.452 & 181.201 \\
\hline
\end{tabular}

(") Inclui outros estados

Tabela 5 - Quantidade total $(\mathrm{kg})$ estimada de caudas de lagostas produzidas por tipo comercial no Brasil, no período de 2005 a 2015.

\begin{tabular}{|c|c|c|c|c|c|c|c|c|c|c|c|c|c|c|}
\hline \multirow{2}{*}{ Ano } & \multicolumn{13}{|c|}{ Categoria Comercial } & \multirow{2}{*}{$\begin{array}{l}\text { Total } \\
\text { Geral }\end{array}$} \\
\hline & 2 & 3 & 4 & 5 & 6 & 7 & 8 & 9 & $10 / 12$ & $14 / 12$ & $14 / 16$ & $16 / 20$ & 20/UP & \\
\hline 2005 & 540 & 60.694 & 197.792 & 162.837 & 211.448 & 213.973 & 181.535 & 228.566 & 526.257 & 288.638 & 161.593 & 116.852 & 53.273 & 2.403 .998 \\
\hline 2006 & .854 & 94.490 & 309.490 & 259.383 & 222.025 & 208.025 & 154.276 & 181.665 & 378.034 & 184.253 & 124.948 & 74.700 & 24.156 & 2.21 \\
\hline 2007 & 3.790 & 95.742 & 294.306 & 368.776 & 298.017 & 264.042 & 48 & 194.083 & 434.970 & 119.112 & 44.384 & 42.268 & 4.629 & 2.3 \\
\hline 2008 & 1.198 & 49.198 & 295.708 & 399.339 & 298.963 & 255.028 & 195.400 & .570 & 330.886 & 186 & 97.443 & 54.999 & 2. & 2.3 \\
\hline 2009 & 276 & 52.852 & 301.569 & 311.820 & 355.599 & 235.076 & 204.152 & 169.732 & 254.121 & 108.767 & 55.137 & 33.001 & 1.054 & 2.0 \\
\hline 2010 & 49 & 73.907 & 724 & 223.594 & 213.203 & 257.630 & 363.780 & .889 & 496.533 & 237.816 & 27 & 102.633 & . & 611 \\
\hline 2011 & 8.013 & 110.316 & 256.635 & 282.157 & 233.033 & 228.899 & 225.180 & 237.836 & 393.276 & 200.693 & 118.125 & 61.935 & 7.063 & 2.363 .162 \\
\hline 2012 & 0 & 72.471 & 164.590 & 211.695 & 176.811 & 157.694 & 244.178 & 180.101 & 189.760 & 110.932 & 40.181 & 30.347 & 2.359 & 1.58 \\
\hline 2013 & 160 & 96.090 & 285.648 & 270.822 & 587.650 & 164.545 & 171.911 & 118.192 & 167.994 & 107.158 & 30.931 & 26.540 & 30 & 2.027 .772 \\
\hline 2014 & 151 & 24.563 & 155.653 & 214.518 & 238.275 & 204.965 & 235.564 & 203.571 & 355.294 & 112.267 & 112.444 & 69.277 & 219 & 1.926 .761 \\
\hline 2015 & 0 & 63.298 & 239.507 & 223.716 & 208.315 & 185.878 & 160.178 & 132.002 & 320.773 & 121.821 & 90.824 & 95.758 & 2.167 & 1.944 .236 \\
\hline
\end{tabular}

Tabela 6 - Número estimado de P. argus capturadas por classe de comprimento total nas pescarias de lagostas na costa brasileira e peso médio anual, no período de 2005 a 2015.

\begin{tabular}{|c|c|c|c|c|c|c|c|c|c|c|c|c|}
\hline \multirow{2}{*}{\multicolumn{2}{|c|}{$\begin{array}{c}\text { Classe } \\
\text { Comp (mm) }\end{array}$}} & \multicolumn{11}{|c|}{ Ano } \\
\hline & & \multirow{2}{*}{$\begin{array}{r}2005 \\
19.795\end{array}$} & \multirow{2}{*}{\begin{tabular}{r|}
2006 \\
33.232
\end{tabular}} & \multirow{2}{*}{$\begin{array}{r}2007 \\
30.238\end{array}$} & \multirow{2}{*}{\begin{tabular}{r|}
2008 \\
29.306
\end{tabular}} & \multirow{2}{*}{$\begin{array}{r}2009 \\
34.517\end{array}$} & \multirow{2}{*}{\begin{tabular}{r|}
2010 \\
17.468
\end{tabular}} & \multirow{2}{*}{$\begin{array}{r}2011 \\
28.260\end{array}$} & \multirow{2}{*}{$\begin{array}{r}2012 \\
18.243\end{array}$} & \multirow{2}{*}{\begin{tabular}{r|}
2013 \\
31.358
\end{tabular}} & \multirow{2}{*}{$\begin{array}{r}2014 \\
16.278\end{array}$} & \multirow{2}{*}{$\begin{array}{r}2015 \\
24.470\end{array}$} \\
\hline 180 & 190 & & & & & & & & & & & \\
\hline 190 & 200 & 105.132 & 153.339 & 158.482 & 163.408 & 142.606 & 86.454 & 127.423 & 82.662 & 140.590 & 83.882 & 126.904 \\
\hline 200 & 210 & 799.677 & 1.268 .071 & 1.293 .358 & 1.309 .134 & 1.308 .333 & 742.669 & 1.111 .737 & 739.345 & 1.222 .912 & 705.084 & 990.714 \\
\hline 210 & 220 & 737.795 & 1.127 .192 & 1.402 .643 & 1.476 .336 & 1.306 .606 & 848.610 & 1.121 .523 & 806.401 & 1.279 .904 & 824.224 & 938.428 \\
\hline 220 & 230 & 809.518 & 1.078 .045 & 1.435 .776 & 1.504 .430 & 1.442 .522 & 947.386 & 1.135 .551 & 845.443 & 1.764 .884 & 961.403 & 941.740 \\
\hline 230 & 240 & 693.149 & 758.527 & 1.004 .783 & 1.020 .623 & 1.072 .260 & 781.894 & 814.121 & 613.088 & 1.424 .842 & 766.204 & 699.537 \\
\hline 240 & 250 & 697.799 & 690.249 & 854.802 & 878.577 & 868.480 & 914.423 & 790.228 & 617.175 & 846.936 & 740.473 & 634.689 \\
\hline 250 & 260 & 762.544 & 688.486 & 771.090 & 827.414 & 816.102 & 1.126 .912 & 860.849 & 734.541 & 684.290 & 817.468 & 625.955 \\
\hline 260 & 270 & 807.142 & 664.081 & 697.392 & 713.645 & 700.824 & 1.143 .701 & 850.746 & 706.101 & 565.007 & 799.831 & 573.261 \\
\hline
\end{tabular}




\begin{tabular}{|c|c|c|c|c|c|c|c|c|c|c|c|c|}
\hline 270 & 280 & 792.797 & 610.550 & 678.931 & 597.795 & 524.503 & 900.668 & 712.458 & 475.951 & 381.763 & 640.276 & 506.065 \\
\hline 280 & 290 & 632.656 & 462.234 & 507.930 & 437.597 & 347.877 & 651.498 & 512.906 & 302.504 & 247.194 & 452.127 & 384.781 \\
\hline 290 & 300 & 518.669 & 368.890 & 377.266 & 343.368 & 258.109 & 505.005 & 402.933 & 223.782 & 188.973 & 337.430 & 296.287 \\
\hline 300 & 310 & 494.548 & 339.429 & 299.972 & 316.220 & 215.951 & 443.787 & 362.982 & 189.218 & 170.413 & 273.839 & 257.129 \\
\hline 310 & 320 & 359.155 & 241.033 & 160.873 & 225.669 & 139.628 & 303.789 & 254.801 & 130.582 & 121.225 & 172.293 & 170.226 \\
\hline 320 & 330 & 260.564 & 182.452 & 104.113 & 161.324 & 96.617 & 218.129 & 185.342 & 85.099 & 75.633 & 144.370 & 134.111 \\
\hline 330 & 340 & 169.136 & 125.315 & 55.207 & 99.452 & 58.192 & 138.830 & 119.333 & 45.460 & 36.975 & 109.459 & 96.282 \\
\hline 340 & 350 & 85.467 & 60.279 & 27.169 & 45.361 & 26.245 & 69.879 & 53.650 & 21.695 & 17.725 & 53.139 & 55.794 \\
\hline 350 & 360 & 59.275 & 40.009 & 18.913 & 27.477 & 16.109 & 47.254 & 31.988 & 14.195 & 11.882 & 33.271 & 41.448 \\
\hline 360 & 370 & 53.794 & 33.818 & 15.173 & 19.268 & 12.042 & 37.557 & 23.832 & 10.550 & 8.652 & 24.770 & 33.437 \\
\hline 370 & 380 & 50.584 & 30.109 & 13.738 & 17.013 & 10.429 & 33.153 & 21.007 & 9.528 & 7.729 & 21.311 & 29.240 \\
\hline 380 & 390 & 38.427 & 22.077 & 9.069 & 10.475 & 7.256 & 23.170 & 14.576 & 5.882 & 4.568 & 14.694 & 19.661 \\
\hline 390 & 400 & 31.287 & 17.899 & 7.073 & 7.971 & 5.624 & 18.103 & 11.387 & 4.511 & 3.442 & 11.332 & 15.262 \\
\hline 400 & 410 & 12.454 & 5.326 & 1.929 & 1.841 & 1.077 & 4.065 & 2.906 & 1.225 & 735 & 1.910 & 2.682 \\
\hline 410 & 420 & 9.004 & 3.662 & 1.166 & 946 & 648 & 2.542 & 1.862 & 674 & 323 & 1.087 & 1.441 \\
\hline 420 & 430 & 1.189 & 533 & 103 & 51 & 24 & 166 & 158 & 53 & 3 & 5 & 47 \\
\hline 430 & 440 & 704 & 228 & 60 & 27 & 14 & 98 & 94 & 31 & 2 & 3 & 1 \\
\hline \multicolumn{2}{|c|}{ Total } & 9.002 .260 & 9.005 .065 & 9.927.249 & 10.234 .730 & 9.412 .594 & 10.007 .211 & 9.552 .653 & 6.683 .938 & 9.237 .962 & 8.006.162 & 7.599 .590 \\
\hline \multicolumn{2}{|c|}{ Peso Médio Cauda } & 0,264 & 0,260 & 0,240 & 0,219 & 0,210 & 0,254 & 0,252 & 0,215 & 0,202 & 0,236 & 0,000 \\
\hline
\end{tabular}

A conversão dos números por classe de comprimento para números por idade, feita a partir a curva de crescimento e dos pesos médios de cada classe, resultou na estrutura etária mostrada na Tabela 7. Verifica-se que os desembarques são compostos pelos grupos de idades de 2 a 10 anos, ficando evidente a predominância das idades 3 e 4, com importante contribuição, também, da idade 5 .

Tabela 7 - Número estimado de P. argus capturadas por idade nas pescarias de lagostas na costa brasileira, no período de 2005 a 2015.

\begin{tabular}{|c|c|c|c|c|c|c|c|c|c|c|c|}
\hline \multirow{2}{*}{ Idade } & \multicolumn{11}{|c|}{ Ano } \\
\hline & 2005 & 2006 & 2007 & 2008 & 2009 & 2010 & 2011 & 2012 & 2013 & 2014 & 2015 \\
\hline 2 & 33.232 & 33.232 & 30.238 & 29.306 & 34.517 & 17.468 & 28.260 & 18.243 & 31.358 & 16.278 & 24.470 \\
\hline 3 & 3.145 .270 & 4.385 .174 & 5.295 .042 & 5.473 .932 & 5.272 .327 & 3.407 .013 & 4.310 .355 & 3.086 .939 & 5.833 .133 & 3.340 .797 & 3.697 .322 \\
\hline 4 & 3.060 .283 & 2.653 .366 & 3.002 .214 & 3.017 .431 & 2.909 .909 & 4.085 .704 & 3.214 .281 & 2.533 .768 & 2.477 .996 & 2.998 .048 & 2.339 .970 \\
\hline 5 & 1.645 .873 & 1.170 .554 & 1.185 .168 & 1.097 .184 & 821.937 & 1.600 .291 & 1.278 .821 & 715.505 & 606.580 & 1.063 .396 & 938.197 \\
\hline 6 & 788.854 & 548.800 & 320.192 & 486.445 & 294.438 & 660.748 & 559.476 & 261.140 & 233.833 & 426.122 & 400.618 \\
\hline 7 & 144.742 & 100.288 & 46.082 & 72.839 & 42.353 & 117.133 & 85.638 & 35.890 & 29.607 & 86.410 & 97.243 \\
\hline 8 & 104.378 & 63.927 & 28.911 & 36.282 & 22.470 & 70.711 & 44.840 & 20.077 & 16.382 & 46.081 & 62.677 \\
\hline 9 & 38.427 & 22.077 & 9.069 & 10.475 & 7.256 & 23.170 & 14.576 & 5.882 & 4.568 & 14.694 & 19.661 \\
\hline 10 & 54.638 & 27.648 & 10.331 & 10.836 & 7.387 & 24.974 & 16.406 & 6.493 & 4.505 & 14.337 & 19.432 \\
\hline
\end{tabular}

A análise sequencial de população indica que a abundância anual da população nas idades 2 a 10 girou em torno de 42,9 milhões de indivíduos no período (Tabela 8), verificando-se, porém, uma queda acentuada em 2011, quando atingiu apenas 37,1 milhões de indivíduos. A partir de 2012, a abundância volta a aumentar, observando-se de 2013 a 2015 valores acima da média do período analisado, com números acima de 45 milhões de indivíduos para os grupos de idade 2 a 10+ e biomassa acima de 20 mil toneladas em 2014 e 2015. 
Tabela 8 - Estimativa do número de P. argus que compunham o estoque de lagostas, por idade, biomassa ( $t$ ) e rendimento (t), na costa brasileira, no período de 2005 a 2015 .

\begin{tabular}{|c|c|c|c|c|c|c|c|c|c|c|c|}
\hline \multirow{2}{*}{ Idade } & \multicolumn{11}{|c|}{ Ano } \\
\hline & 2005 & 2006 & 2007 & 2008 & 2009 & 2010 & 2011 & 2012 & 2013 & 2014 & 2015 \\
\hline 1 & 24.219 .685 & 27.639 .876 & 26.367 .616 & 28.451 .934 & 20.753.389 & 22.970 .841 & 28.928 .894 & 30.773 .747 & 24.064 .843 & 29.480 .553 & \\
\hline 2 & 16.525 .452 & 17.688 .043 & 20.185 .865 & 19.256 .712 & 20.778 .925 & 15.156 .548 & 16.775 .990 & 21.127 .257 & 22.474 .584 & 17.574 .959 & 21.530 .143 \\
\hline 3 & 13.947 .164 & 12.061 .263 & 12.908 .484 & 14.738 .955 & 14.057 .291 & 15.176 .599 & 11.058 .186 & 12.238 .860 & 15.430 .407 & 16.419 .214 & 12.835 .359 \\
\hline 4 & 6.716 .904 & 5.979 .584 & 5.026 .095 & 6.216 .341 & 6.654 .405 & 7.372 .470 & 5.883 .378 & 4.202 .338 & 6.348 .220 & 8.684 .884 & 8.404 .071 \\
\hline 5 & 2.503 .726 & 2.228 .296 & 1.901 .939 & 1.980 .404 & 2.226 .298 & 2.974 .963 & 2.107 .063 & 1.632 .651 & 1.848 .235 & 3.150 .896 & 3.745 .271 \\
\hline 6 & 893.046 & 830.231 & 708.430 & 749.152 & 708.972 & 995.030 & 849.803 & 584.399 & 717.854 & 917.161 & 1.358 .393 \\
\hline 7 & 348.069 & 296.132 & 263.951 & 279.042 & 268.192 & 316.871 & 284.232 & 235.695 & 256.952 & 356.225 & 395.400 \\
\hline 8 & 192.416 & 115.419 & 94.148 & 103.967 & 99.895 & 119.867 & 90.515 & 78.832 & 103.632 & 127.509 & 153.573 \\
\hline 9 & 116.157 & 63.805 & 36.694 & 37.084 & 37.220 & 44.648 & 34.240 & 25.104 & 34.661 & 51.426 & 54.971 \\
\hline 10 & 114.078 & 38.518 & 20.285 & 14.454 & 13.276 & 16.635 & 12.754 & 9.497 & 11.038 & 17.200 & 22.170 \\
\hline \multicolumn{12}{|c|}{ Idades 2 a $10+$} \\
\hline Número (2:10 & 41.357.011 & 39.301 .290 & 41.145 .892 & 43.376 .112 & 44.844 .473 & 42.173 .630 & 37.096 .161 & 40.134 .633 & 47.225 .583 & 47.299 .473 & 48.499 .349 \\
\hline Biomassa (t) & 19.029 & 16.957 & 16.313 & 17.948 & 18.422 & 19.787 & 16.002 & 15.001 & 18.648 & 21.853 & 22.255 \\
\hline Rendimento & 7.104 & 6.204 & 6.279 & 6.574 & 5.749 & 7.493 & 6.597 & 4.387 & 5.302 & 5.618 & 5.199 \\
\hline
\end{tabular}

A abundância estimada na idade 2, quando os indivíduos começam a ser capturados, considerada aqui a idade de início do recrutamento para a pesca, oscilou em torno de uma média de 19,0 milhões de indivíduos, apresentando expressiva diminuição nos anos de 2010 e 2011, com 15,2 e 16,8 milhões de indivíduos respectivamente. Recuperou-se nos dois anos seguintes, atingindo um pico de 21,1 milhões de indivíduos, em 2013, mas volta a cair acentuadamente em 2014, com apenas 17,6 milhões de indivíduos, mas volta a se recuperar em 2015 em função do elevado recrutamento no ano anterior. Os números na idade 4, onde os indivíduos estão totalmente recrutados à pesca, giram em torno de uma média de 6,5 milhões, com uma queda acentuada entre 2011 e 2013. Em 2012 verifica-se o menor valor de todo o período, 4,2 milhões de indivíduos. Nos dois anos seguintes, o número de indivíduos na idade 4 volta a se recuperar, atingindo novo pico de 8,7 milhões de indivíduos em 2014. Os números estimados na idade 1 foram calculados considerando-se a mesma taxa de mortalidade estimada para a idade 2 e apresentam média de 26,4 milhões de indivíduos, com certa de estabilidade até 2008. No ano de 2009 observa-se uma diminuição acentuada para cerca de 20,8 milhões de indivíduos, seguida de expressiva recuperação a partir daí. Em 2012 o número de indivíduos na idade 1 atinge o pico de 30,8 milhões de indivíduos. Em 2013 cai para 24,1 milhões de indivíduos, mas volta a se recuperar em 2014 atingindo 29,4 milhões de indivíduos (Tabela 8).

As mortalidades por pesca estimadas, para cada grupo de idade, nas pescarias de lagosta na costa brasileira, no período de 2005 a 2015 (Tabela 9), indicam para a idade 4, considerada idade de recrutamento total à pesca, que as mortalidades por pesca variaram de 0,387, em 2013, menor valor do período, a valores máximos acima de 0,9 , em 2010 e 2011, significando, possivelmente, uma forte redução da abundância naqueles anos. Nos anos seguintes apresenta expressiva queda, com valores girando em torno de 0,5. 
Tabela 9 - Mortalidades por pesca estimadas, nas pescarias de P. argus na costa brasileira, no período de 2005 a 2015.

\begin{tabular}{|c|c|c|c|c|c|c|c|c|c|c|c|}
\hline \multirow{2}{*}{ Idade } & \multicolumn{11}{|c|}{ Ano } \\
\hline & 2005 & 2006 & 2007 & 2008 & 2009 & 2010 & 2011 & 2012 & 2013 & 2014 & 2015 \\
\hline 2 & 0,002 & 0,002 & 0,001 & 0,002 & 0,001 & 0,002 & 0,002 & 0,001 & 0,001 & 0,001 & 0,001 \\
\hline 3 & 0,534 & 0,562 & 0,418 & 0,482 & 0,332 & 0,635 & 0,655 & 0,343 & 0,262 & 0,357 & 0,358 \\
\hline 4 & 0,790 & 0,832 & 0,618 & 0,714 & 0,492 & 0,939 & 0,969 & 0,508 & 0,387 & 0,528 & 0,530 \\
\hline 5 & 0,791 & 0,833 & 0,619 & 0,714 & 0,492 & 0,940 & 0,969 & 0,509 & 0,388 & 0,528 & 0,531 \\
\hline 6 & 0,791 & 0,833 & 0,619 & 0,714 & 0,492 & 0,940 & 0,969 & 0,509 & 0,388 & 0,528 & 0,531 \\
\hline 7 & 0,791 & 0,833 & 0,619 & 0,714 & 0,492 & 0,940 & 0,969 & 0,509 & 0,388 & 0,528 & 0,531 \\
\hline 8 & 0,791 & 0,833 & 0,619 & 0,714 & 0,492 & 0,940 & 0,969 & 0,509 & 0,388 & 0,528 & 0,531 \\
\hline 9 & 0,791 & 0,833 & 0,619 & 0,714 & 0,492 & 0,940 & 0,969 & 0,509 & 0,388 & 0,528 & 0,531 \\
\hline 10 & 0,791 & 0,833 & 0,619 & 0,714 & 0,492 & 0,940 & 0,969 & 0,509 & 0,388 & 0,528 & 0,531 \\
\hline
\end{tabular}

A estrutura etária da população atual indica uma predominância absoluta das idades 1 a 3 na composição da estrutura da população, com o número bastante reduzido de indivíduos nas idades 4 a 6, quando comparada com a estrutura teórica estimada, para o nível médio de recrutamento atual, caso não houvesse pesca (Figura 1), com a população submetida apenas à mortalidade natural. A partir da idade 7 o número de indivíduos na população atual se torna inexpressivo embora o nível do recrutamento não demonstre acentuada variação ao longo dos anos e, durante o período analisado, e a estrutura da população por idades, embora comprometida, tem mantido certa estabilidade.

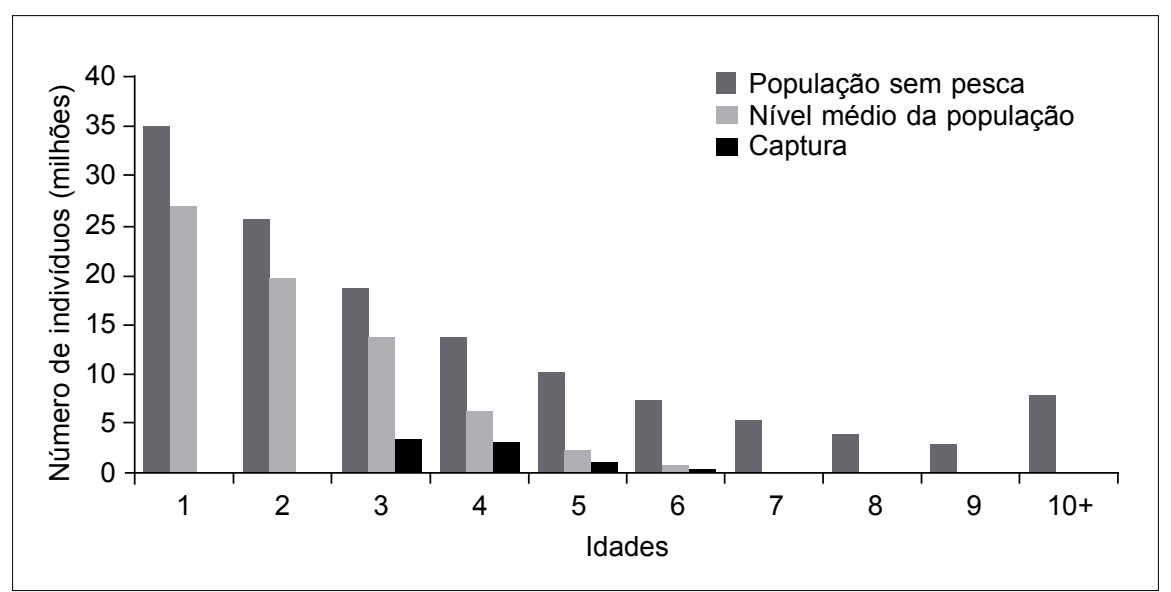

Figura 1 - Composição atual da população de P. argus na costa brasileira comparada com à mortalidade natural, para o nível atual de recrutamento, e capturas observadas em 2015.

O percentual de biomassa reprodutiva estimada da população $P$. argus na costa brasileira, em 2005 foi de 20,9\%, 2006 17,9\%, 2007 16,6\%, 2008 18,9\%, 2009 19,1\%, 2010 22,2\%, 2011 16,9\%, 2012 14,6\% , 2013 19,1\%, 2014 24,3\% e 2015 23,9\%. A redução da abundância de indivíduos adultos, ou mais velhos, resultou, naturalmente, na diminuição do estoque reprodutor da população da lagosta vermelha, e com uma biomassa média, estimada de forma aproximada, durante o período estudado, da ordem de 19,5\%. Os valores mais elevados são observados nos dois últimos anos (2014 e 2015), quando a biomassa reprodutora estimada girou em torno de $24 \%$.

A Figura 2 apresenta o resultado da simulação por "bootstrap" para os valores da mortalidade por pesca. Embora, em geral, os resultados indiquem um ajuste razoável para a maioria dos valores, fica evidente forte incoerência dos valores da mortalidade por pesca 
em relação ao esforço de pesca para os anos 2010 e 2011, sugerindo que, provavelmente, o esforço para esses anos tenha sido subestimado ou que o poder de pesca aumentou muito.

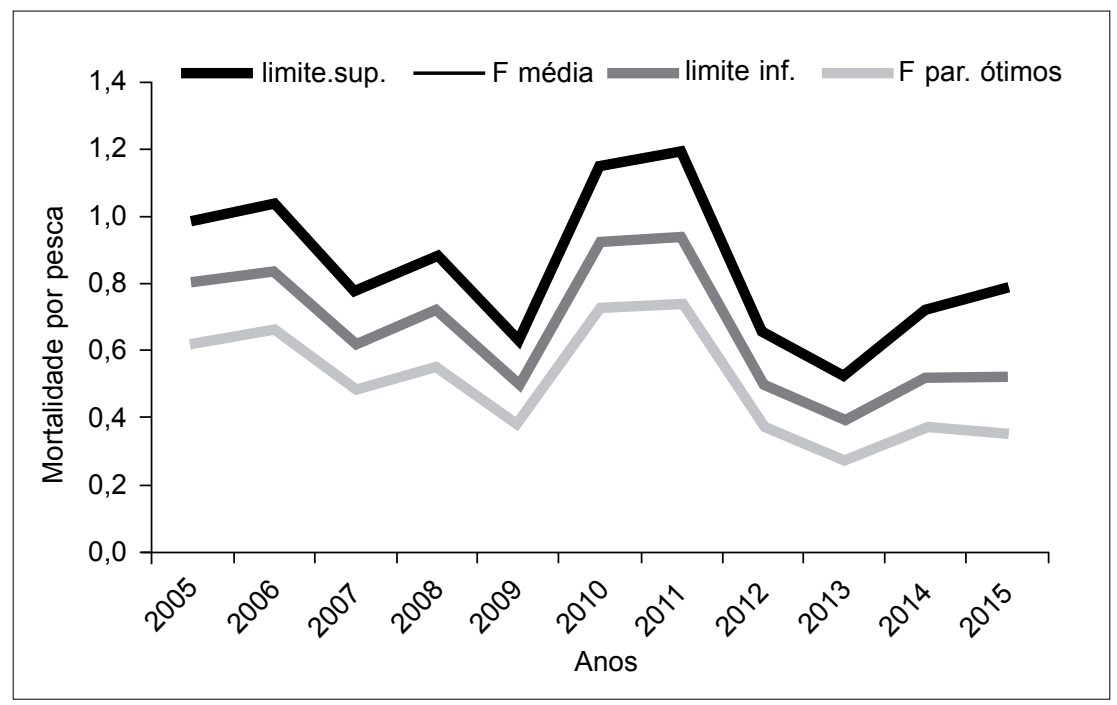

Figura 2 - Intervalo de confiança da mortalidade por pesca total (100\% e retenção) nas pescarias de P. argus, no período de 2005 a 2015.

O intervalo de confiança das estimativas de biomassa, por sua vez, variou dentro de uma faixa relativamente larga durante todo o período, para o nível de confiança de 95\%, evidenciando o nível de incerteza dos resultados. Como exemplo, os valores estimados da biomassa em peso inteiro, para o ano de 2015, neste intervalo, ficaram entre 19.426 e 26.988 $t$, com uma média de $22.827 \mathrm{t}$, enquanto o valor obtido para a estimativa pontual naquele ano ficou em $22.255 \mathrm{t}$ (Figura 3).

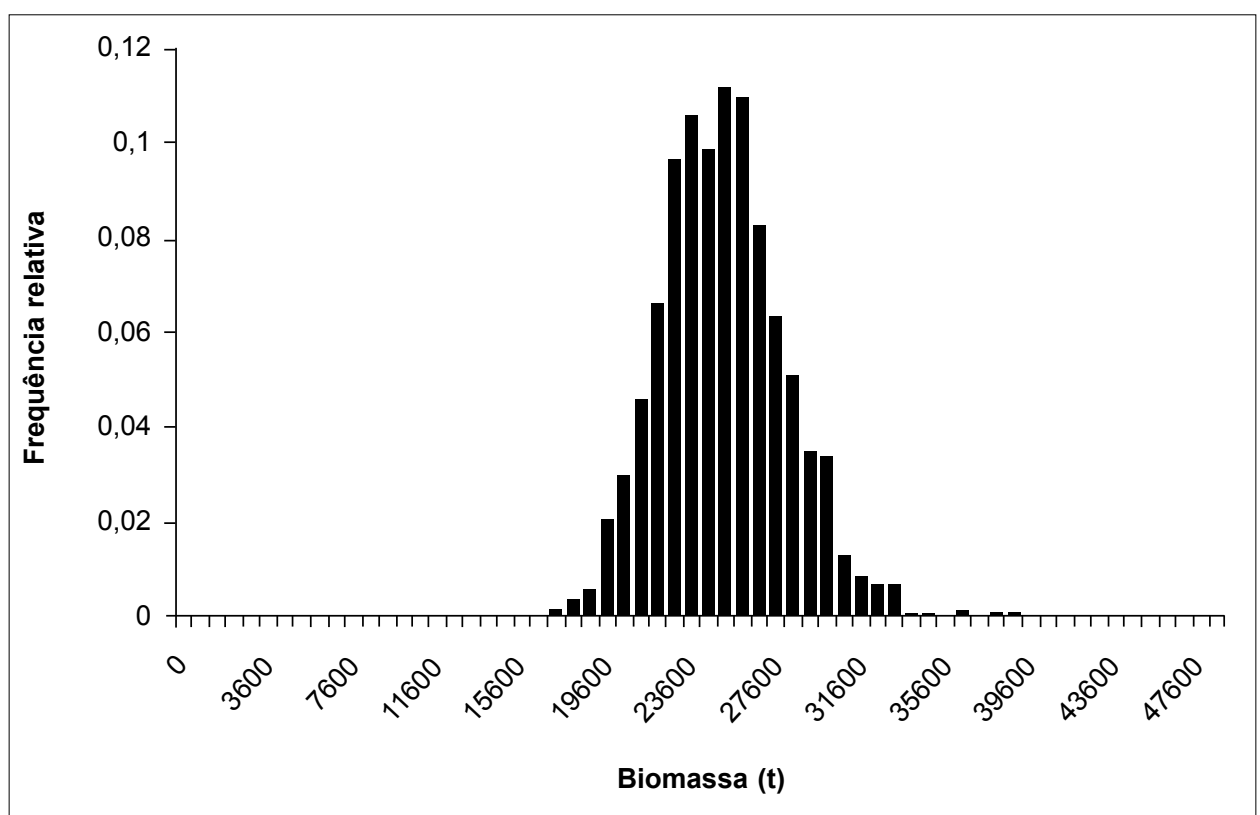

Figura 3 - Faixa de variação dos valores da biomassa de P. argus estimados por "bootstrap" no ano de 2015. 


\section{DISCUSSÃO}

Modelos de avaliação de estoques estruturados por idade do tipo aqui utilizado integram informações sobre a história de vida da população com informações sobre a atividade pesqueira e não assumem recrutamento nem mortalidade constante para diferentes idades (Megrey, 1989). A aplicação destes modelos permite estimar o tamanho da população em cada idade, as taxas de mortalidade por pesca e a seletividade específica por idade, modelando de forma mais realística a dinâmica da pescaria, em comparação com modelos holísticos e outros também baseados no equilíbrio da população. No entanto, modelos estruturados por idade requerem maior quantidade de dados e informações pretéritas e, ainda que mais elaborados, têm também seus resultados reconhecidamente sujeitos a incertezas (Haddon, 2011). Tais incertezas devem ser explicitamente apresentadas, contribuindo para a implementação de ações que possibilitem se obter dados mais informativos e resultados mais consistentes para subsidiar a adoção das medidas de ordenamento para uso dos recursos.

No caso de crustáceos, a aplicação de modelos mais complexos, para a avaliação de estoques é limitada, devido às dificuldades de estimar a idade dos indivíduos (Smith \& Addison, 2003). Ao contrário dos peixes, não se dispõe da possibilidade de inspeção de estruturas de aposição ósseas (ou cartilaginosas) para a contagem de anéis etários, tornando particularmente difícil o discernimento de coortes sobrepostas nas distribuições de frequência e, embora se disponha de técnicas para converter comprimentos em idades, modelos estruturados por idade não têm sido largamente aplicados para crustáceos (Sheehy \& Prior, 2008). Algumas aplicações bem sucedidas, no entanto, podem ser mencionadas como trabalhos com Pandalus (Ices, 2001) e Nephrops (Ices, 2006) e as avaliações de estoque de $P$. argus realizadas em Cuba (Morales-Fadragas, 2005). A aplicação do modelo à $P$. argus na costa brasileira resultou, também, em valiosos subsídios para a identificação de medidas de ordenamento do uso do recurso.

Ao se analisar o rendimento das pescarias de lagostas na costa brasileira se verifica que as capturas oscilam ao longo dos anos, com alguns picos importantes, mas apresentam, de maneira geral, tendência decrescente. A captura de 2015 foi cerca de $32 \%$ menor que o valor mais alto obtido no período aqui analisado. Isto se deve, pelo menos em grande parte, à acentuada redução do esforço de pesca aplicado ao recurso, fortemente dirigida pelo estabelecimento do defeso de seis meses em 2008 (IN 206/2008), pela proibição e consequente programa de compras das caçoeiras adotado pelo Ministério da Pesca, em 2007, assim como pela proibição de importação de lagosta abaixo do "tipo 5" por parte dos Estados Unidos da América, em 2008.

Embora aqui o esforço de pesca tenha sido estimado com base na CPUE nominal das lanchas operando com caçoeira, que apresenta seus níveis de incerteza, devido ao dinâmico padrão das pescarias, deve-se notar que a caçoeira é hoje o petrecho de pesca mais utilizado na pescaria como um todo e a produção de lagostas se origina principalmente das lanchas (barcos) motorizados. Além do mais, as estimativas foram obtidas a partir de grande volume de dados de dias de mar e captura por viagem, controlados pelo programa ESTATPESCA, e os valores de CPUE's refletem, pelo menos, as tendências gerais de rendimento das pescarias.

Assim, se considerou razoável utilizá-los como índice aproximado de abundância relativa. Em relação às mortalidades por pesca impostas ao estoque de lagosta da costa brasileira, as estimativas aqui encontradas indicam que superam muito, em alguns anos, a 
mortalidade natural de 0,32 por ciclo ano, estimada anteriormente por Ivo \& Pereira (1996). De fato, a partir da idade 4, as mortalidades por pesca, entre 2005 e 2008, se mantiveram bastante elevadas chegando 0,83 ao ano. Em 2009, logo após o estabelecimento das medidas de regulamentação já citadas, verifica-se uma queda brusca, com as máximas em torno de 0,5 ao ano. Um novo incremento ocorre nos anos seguintes, atingindo o pico de 0,97 ao ano, em 2011, valor que supera a mortalidade natural em mais de três vezes. Nos últimos quatro anos do período analisado a mortalidade por pesca volta a diminuir para níveis em torno de 0,5 , ainda acima da mortalidade natural, mas bem mais próximos. Após 2009, as oscilações talvez estejam mais relacionadas a variações na abundância do estoque, dada forte tendência de redução do esforço de pesca até aquele ano e a estabilidade nos anos seguintes. A título de comparação, Muller et al. (1997) estimaram mortalidades por pesca de $\mathrm{F}=0,59$ por ano e $\mathrm{F}=0,33$ por ano em duas regiões da Flórida.

Mortalidades por pesca elevadas nas pescarias de lagostas são comumente observadas, sendo a maioria das pescarias caracterizadas por altas taxas de explotação, o que leva a alterações substanciais na estrutura por tamanho das populações, com a diminuição do tamanho médio ao longo do tempo, à medida que os indivíduos maiores vão sendo removidos (Frusher \& Hoenig, 2001). Isto se aplica também à estrutura da população de lagosta na costa brasileira, com indicativos de que hoje é composta predominantemente por indivíduos mais jovens, conforme os resultados do presente estudo. Obviamente, isso se reflete nas capturas, majoritariamente compostas também por indivíduos jovens, sendo um indício de que poderia estar havendo sobrepesca de crescimento, o que sugere uma forte dependência da pesca aos níveis de recrutamento anual e uma falha expressiva do mesmo pode ter resultados bastante indesejáveis para a população e para a atividade.

A comparação da estrutura populacional atual com a estrutura potencial da população sem pesca, que seria representativa do equilíbrio, em condições naturais, sugere que a estrutura atual apresenta declínios substanciais na composição por tamanhos, embora pareça apresentar certa estabilidade ao longo do tempo. De fato, a biomassa estimada dos indivíduos com tamanho acima do tamanho de primeira maturação, considerado aqui uma "estimativa grosseira" do estoque reprodutor, que seria um indicativo aproximado do potencial reprodutivo da espécie, se apresenta bastante reduzida durante o período. Em média representou pouco mais de 19,5\% do estoque reprodutor correspondente à biomassa prístina estimada, sendo o maiores valores, estimados em cerca de $24 \%$, observados nos anos 2014 e 2015. Embora não haja referências a crustáceos, alguns autores consideram críticos, para peixes, valores de biomassa reprodutiva abaixo da faixa de $25 \%$ a $45 \%$ da biomassa virgem, dependendo da espécie (Caddy \& Mahon, 1995).

Se para alguns recursos um nível de biomassa abaixo de $40 \%$ do estoque reprodutor pode ser considerado muito baixo, parece ser comum que isso ocorra nas populações de lagostas. Ou seja, mesmo com baixo nível de estoque reprodutor o recurso conseguiria manter um nível razoavelmente estável de recrutamento. De fato, o recrutamento da lagosta vermelha na costa brasileira não apresenta oscilações bruscas, embora possam ser consideradas expressivas em alguns anos.

De acordo com Cobb \& Caddy (1989), isso pode ser explicado pela natureza assintótica da equação proposta por Beverton-Holt, que melhor descreve a relação "estoque reprodutor-recrutamento" para lagosta espinhosa. Este argumento poderia justificar a estabilidade do estoque, bem como sua resiliência a elevadas taxas contínuas de explotação, sugerindo que níveis relativamente elevados de mortalidade por pesca podem ser sustentáveis, até certo limite, sem que se observe uma diminuição expressiva do recrutamento. González et al. 
(1991) sugerem também que, por estarem em águas mais profundas, boa parte do estoque reprodutor sofre menor taxa de explotação, o que lhe confere certa proteção.

A relativa estabilidade da população também é evidenciada pela variação não muito acentuada do número de indivíduos no estoque e da biomassa total. A população em número variou de 37,1 milhões de indivíduos e uma biomassa total de 16,0 mil toneladas, em 2011, a 48,5 milhões de indivíduos e uma biomassa total de 22,3 mil toneladas, em 2015. Isso sugere que, ainda considerando as incertezas, há indícios de certa recuperação da população no final da série temporal analisada. Mas, a recuperação da estrutura da população a níveis mais seguros, um meta absolutamente desejável e necessária, está na dependência da manutenção de baixos níveis de esforço de pesca e eliminação das práticas predatórias, com a consequentemente diminuição da mortalidade por pesca, especialmente sobre os indivíduos mais jovens.

Deve-se ressaltar que, apesar das imprecisas estimativas de esforço de pesca, parece razoável concluir que houve, de fato, expressiva redução do mesmo no período considerado e, se este quadro continuar, é possível que um processo de recuperação da população venha a se confirmar e os rendimentos das pescarias venham a melhorar. Isto ocorreu na Flórida, onde o número de armadilhas utilizadas e o número de viagens de pesca foram reduzidos (Muller et al., 1997). As estatísticas mostram que, na costa brasileira, rendimentos bem maiores já foram obtidos no passado e os estudos realizados anteriormente apontam para a possibilidade de rendimentos potenciais mais elevados.

Embora o ajuste do modelo aqui utilizado não possa ser considerado totalmente satisfatório, tendo em vista algumas discrepâncias das estimativas de CPUE em relação àquelas observadas e às mortalidades por pesca, é necessário enfatizar que os resíduos das capturas estimadas, em número e peso, em relação àquelas observadas, não apresentaram qualquer evidência de viés. E, embora as capturas isoladamente não sejam, às vezes, suficientes para que se obtenham resultados acurados sobre a composição do estoque, sendo recomendada a inclusão de outros índices de calibração (Haddon, 2011), vale ressaltar que simulações com a utilização de diferentes pesos para a CPUE, não provocaram alterações importantes nos resultados finais que, por isso, podem ser considerados bastante satisfatórios. Os resultados finais aqui apresentados foram obtidos com atribuição de peso 0,5 para a contribuição dos resíduos da CPUE durante o processo de ajuste. Alguns aspectos importantes, não considerados nas análises, dizem respeito ao impacto do padrão de pesca. A caçoeira é o principal petrecho utilizado e considerado extremamente predatório, por seus efeitos negativos sobre o estoque e principalmente sobre o habitat da lagosta. A incorporação dos atratores artificiais (marambáias) como acessórios auxiliares na pescaria aumentou, certamente, o poder de pesca das embarcações, principalmente no Ceará, e isto não se reflete no esforço nominal em termos de dias de mar. Também não são incorporadas variáveis ambientais no modelo, cuja influência na abundância das populações de organismos aquáticos, em geral, tem sido claramente evidenciada.

A possibilidade de estarmos lidando com mais de um estoque de $P$. argus é outro fator de incertezas ao se aplicar os modelos considerando um único estoque. Andrade (2015) sugere que três cenários diferentes podem ser identificados na costa brasileira: a) um único estoque; b) uma combinação de vários estoques; c) grupos habitando áreas com fontes comuns de larvas (metapopulação). Nenhuma destas três hipóteses pode ser descartada, embora não existam estudos que possam confirmar qualquer uma delas para o estoque na costa brasileira. Deve-se considerar, também, a possibilidade das larvas serem levadas pelas correntes e, portanto, assumirem ampla distribuição. 
Um estudo apresentado por Diniz et al. (2005), por exemplo, apresenta evidências de que as lagostas capturadas próximo à linha do equador e aquelas encontradas a aproximadamente $20^{\circ} \mathrm{S}$ podem se constituir de diferentes linhagens. Nesse estudo, porém, foi utilizada uma amostra muito pequena e os resultados devem ser encarados com cautela. Com relação ao estoque de lagostas do Caribe, entretanto, existem, sim, comprovações de que se tratam de grupos diferentes, inclusive compostos por duas subespécies: $P$. argus argus no Caribe; e P. argus westonii no Brasil (Sarver et al., 2000). Por sua vez, Giraldes \& Smyth (2016) reclassificaram a lagosta vermelha como Panulirus meripurpuratus, com ocorrência restrita à costa brasileira.

A curva de seletividade adotada no ajuste do modelo é do tipo proposto por BevertonHolt, embora outros autores proponham curvas diferentes para a lagosta. Puga et al. (1996), por exemplo, descrevem uma curva assimétrica, em forma de sino, para a seletividade de P. argus em águas cubanas. Frusher \& Hoenig (2001) sugerem diferentes padrões para as curvas de seletividade da Jasus edwardsii, indicando variações espaço temporais, e também diferenças entre machos e fêmeas. Afirmam que isso resulta em incertezas nas estimativas do recrutamento e a utilização de curvas de seletividade fixas nos modelos de avaliação de estoques precisa ser melhor investigada. No presente caso, no entanto, a incorporação da curva de seletividade do tipo Berverton-Holt ao modelo utilizado não apresentou expressivo impacto nos resultados ou, pelo menos, não apresentou contradição com as outras fontes de dados disponíveis.

As simulações com a técnica de "bootstrap" permitiram avaliar o grau de incerteza das estimativas, aspecto que não tem sido levado em consideração em outros trabalhos baseados em pressupostos irreais de equilíbrio. Os resultados apresentaram variações dentro de intervalos de confiança relativamente estreitos e não sugerem inconsistências ou não indicam uma situação alarmante do nível atual do estoque. Mas, somente quando se dispuser de dados mais consistentes e realistas, será possível obter resultados com níveis mais elevados de acuidade. Além de levantamentos extensivos de dados da atividade comercial, são fundamentais dados complementares não dependentes da pesca, obtidos por meio de cruzeiros de pesquisa e dados sobre as fases iniciais de vida, especialmente sobre áreas e intensidade de assentamento de puerulus na costa.

\section{REFERÊNCIAS}

Andrade, H.A. Stock assessment of the red spiny lobster (Panulirus argus) caught in the tropical southwestern Atlantic. Lat. Am. J. Aquat. Res., v. 43, n. 1, p. 201-214, 2015.

Caddy, J.F. \& Mahon, R. Reference points for fisheries management. FAO Fisheries Technical Paper. (347), 83 p, 1995.

Castro-Silva, S.M.M. \& Rocha, C.A.S. Embarcações, aparelhos e métodos de pesca utilizados nas pescarias de lagosta no Ceará. Arq. Ciên. Mar., Fortaleza, v. 32, n. 12, p. 1-21, 1999.

Cedepesca - Centro de Desenvolvimento e Pesca Sustentável do Brasil. Avaliação do estoque de lagosta vermelha e recomendações de gestão. Relatório Técnico, 12 p., 2014.

Cobb, J.S. \& Caddy, J.F. The population biology of decapods. In: Caddy, J.F. (ed.) Marine Invertebrate Fisheries: Their assessment and management. New York, 327374 p., 1989.

Cruz, R.; Silva, K.C.A. \& Cintra, I.H.A. Assessment of wild spiny lobster stocks on the Brazilian continental shelf. Crustaceana, v. 86, n. 3, p. 336-356, 2013. 
Diniz, F.M.; Maclean, N.; Ogawa, M.; Cintra, I.H.A. \& Bentzen, P. The hypervariable domain of the mitochondrial control region in Atlantic spiny lobsters and its potential as marker for investigating phylogeographic structuring. Mar. Biotechnol., v. 7, p. 462-473, 2005.

Ehrhardt, N.M. \& Aragão, J.A.N. Brazil spine lobster P. argus fishery. In: Results of a Regional FAO Workshop on the Assessment and Management of the Caribbean Spiny Lobster (Panulirus argus). Executive summary. Mérida: FAO. 19-29 p., 2007.

Frusher, S.D. \& Hoenig, J.M. Impact of lobster size on selectivity of traps for southern rock lobster (Jasus edwardsii). Can. J. Fish. Aquat. Sci., v. 58, p. 2482-2489, 2001.

Giraldes, B.W. \& Smyth, D.M. Recognizing Panulirus meripurpuratus sp. nov. (Decapoda: Palinuridae) in Brazil-Systematic and biogeographic overview of Panulirus species in the Atlantic Ocean. Zootaxa, v. 4107, n. 3, p. 353-366, 2016.

González, G., Herrera, A.; Díaz, E.; Brito, R.; Gotera, G.; Arrinda, C. \& Ibarzábal, D. Biología y conducta de la langosta (Panulirus argus, Lat.) en las zonas profundas del borde de la plataforma en la región suroccidental de Cuba. Rev. Invest. Mar., v. 12, n. 1-3, p. 140-153, 1991. Haddon, M. Modelling and quantitative methods in fisheries. New York. 465 p., 2011.

Ices - International Council for the Exploration of the Sea. Report of the Pandalus Assessment Working Group. ICES CM 2001/ ACFM: 04.68 p., 2001.

Ices - International Council for the Exploration of the Sea. Report of the Working Group on Nephrops Stocks, ICES CM 2001/ ACFM: 16. 1182 p., 2006.

Ivo, C.T.C. \& Pereira, J.A. Crescimento e idade das lagostas Panulirus argus (Latreille) e Panulirus laevicauda (Latrille) no norte e nordeste do Brasil. Arq. Ciên. Mar., Fortaleza, v. 30, n. $1 / 2$, p. 33-39, 1996.

Ivo, C.T.C.; Fonteles-Filho, A.A.; Silva, A.C. \& Vieira, R.H.S.F. Cadeia produtiva da lagosta nas regiões norte e nordeste do Brasil. RDS Editora, 216 p., Fortaleza, 2013.

Mdict-ALiceweb. Sistema de análise das informações de comércio exterior via internet do Ministério do Desenvolvimento, Indústria e Comércio Exterior. Disponível em: http:// aliceweb.desenvolvimento.gov.br/. Acesso: em 25 abril 2016, 2015.

Mdict-Aliceweb. Sistema de análise das informações de comércio exterior via internet do Ministério do Desenvolvimento, Indústria e Comércio Exterior. Disponível em: http:// aliceweb.desenvolvimento.gov.br/. Acesso em: 25 abril 2016, 2016.

Megrey, B.A. Review and comparison of age-structured stock assessment models from theoretical and applied points of view. Am. Fish. Soc. Symp., v. 6, p. 8-48, 1989.

Morales-Fadragas, O. Assessment of the spiny lobster (Panulirus argus, Latreille, 1804) in Northeastern Cuban Waters. Final Projec. UNU-Fisheries Training Program. 63 p., 2005.

Muller, R.G.; Hunt, J.H.; Matthews, T.R. \& Sharp, W.C. Sharp Evaluation of effort reduction in the Florida Keys spiny lobster, Panulirus argus, fishery using an agestructured population analysis. Mar. Freshwater Res., p. 48, n. 8, p. 1045-1058, 1997.

Pope, J.G. An investigation of the accuracy of virtual population analysis using cohort analysis. Res. Bull. ICNAF, v. 9, p. 65-74, 1972.

Puga, R.; León, M.E. \& Cruz, R. Catchability for the main fishing methods in the Cuban fishery of the spiny lobster Panulirus argus (Latreille, 1804), and implications for management (Decapods Palinuridea). Crustaceana, v. 69, n. 6, p. 703-718, 1996. 
Sarver, S.K.; Freshwater, D.W. \& Walsh, P.J. The occurrence of the provisional Brazilian subspecies of spiny lobster (Panulirus argus westonii) in Florida waters. Res. Bull., v. 98, p. 870-873, 2000.

Sheehy, M.R.J. \& Prior, A.E. Progress on an old question for stock assessment of the edible crab Cancer pagurus. Mar. Ecol. Prog. Ser., v. 353, p. 191-202, 2008.

Silva, A.C. \& Fonteles-Filho, A.A. Avaliação do defeso aplicado a pesca da lagosta no nordeste do Brasil. 1a Edição. Editora Expressão Gráfica, Fortaleza, 110 p., 2011.

Smith, T.M. \& Addison, T. J. Methods for stock assessment of crustacean fisheries. Fish. Res., v. 63, p. 231-256, 2003.

Sparre, P. \& Venema, S.C. Introduction to tropical fish stock assessment. FAO Fisheries Technical Papers, v. 306, n. 1, 376 p., 1998. 